\title{
Neuropathy target esterase in mouse whole blood as a biomarker of exposure to neuropathic organophosphorus compounds
}

\author{
Galina F. Makhaeva ${ }^{a}$, Elena V. Rudakova ${ }^{a}$, Larisa V. Sigolaeva ${ }^{b}$, \\ llya N. Kurochkin ${ }^{\mathrm{b}}$ and Rudy J. Richardson ${ }^{\text {c,d* }}$
}

\begin{abstract}
The adult hen is the standard animal model for testing organophosphorus (OP) compounds for organophosphorus compound-induced delayed neurotoxicity (OPIDN). Recently, we developed a mouse model for biochemical assessment of the neuropathic potential of OP compounds based on brain neuropathy target esterase (NTE) and acetylcholinesterase (AChE) inhibition. We carried out the present work to further develop the mouse model by testing the hypothesis that whole blood NTE inhibition could be used as a biochemical marker for exposure to neuropathic OP compounds. Because brain NTE and AChE inhibition are biomarkers of OPIDN and acute cholinergic toxicity, respectively, we compared NTE and AChE 20-min IC 50 values as well as $\mathrm{ED}_{50}$ values $1 \mathrm{~h}$ after single intraperitoneal (i.p.) injections of increasing doses of two neuropathic OP compounds that differed in acute toxicity potency. We found good agreement between the brain and blood for in vitro sensitivity of each enzyme as well for the ratios $\mathrm{IC}_{50}(\mathrm{AChE}) / \mathrm{IC}_{50}(\mathrm{NTE})$. Both OP compounds inhibited AChE and NTE in the mouse brain and blood dosedependently, and brain and blood inhibitions in vivo were well correlated for each enzyme. For both OP compounds, the ratio $\mathrm{ED}_{50}(\mathrm{AChE}) / \mathrm{ED}_{50}$ (NTE) in blood corresponded to that in the brain despite the somewhat higher sensitivity of blood enzymes. Thus, our results indicate that mouse blood NTE could serve as a biomarker of exposure to neuropathic OP compounds. Moreover, the data suggest that relative inhibition of blood NTE and AChE provide a way to assess the likelihood that OP compound exposure in a susceptible species would produce cholinergic and/or delayed neuropathic effects. Copyright $\odot 2016$ John Wiley \& Sons, Ltd.
\end{abstract}

Keywords: acetylcholinesterase (AChE); neuropathy target esterase (NTE); OPIDN; biomarkers; blood; brain; mouse; organophosphorus (OP) compounds; poly $(\mathrm{N}, \mathrm{N}$-dimethylaminoethyl methacrylate)

\section{Introduction}

Organophosphorus (OP) compounds covalently phosphylate serine hydrolases, thus inhibiting their function. When this occurs with neuropathy target esterase (EC 3.1.1.5, NTE), followed by an aging process, a distal axonal degeneration ensues. This chemically induced neurodegenerative disease is known as organophosphorus compound-induced delayed neurotoxicity (OPIDN), and OP compounds capable of producing this condition are termed neuropathic. The aging process involves the formation of a negative charge on the organophosphyl moiety covalently attached to the active site serine of NTE (Richardson et al., 2013).

If an OP compound is a substantially more potent inhibitor of acetylcholinesterase (EC 3.1.1.7, AChE) than of NTE, then cholinergic toxicity could result in lethality, thus obviating the development of OPIDN. However, if the OP compound is neuropathic, cholinergic toxicity may be mild, and sufficient NTE can be inhibited and aged to initiate OPIDN (Lotti and Moretto, 2005).

The OPIDN syndrome involves distal sensorimotor degeneration of long large-diameter axons in the spinal cord and peripheral nerves with associated sensory deficits and paralysis occurring within 1-4 weeks after exposure (Richardson and Makhaeva, 2014). Mechanistic research indicates that inhibition and aging of $>70 \%$ of NTE in neural tissue initiates OPIDN and that inactivation of AChE is not involved (Johnson, 1982; Lotti, 1992).
The neuropathic potential of an OP compound is its ability to produce OPIDN. This tendency depends on its relative inhibitory potency (RIP) towards NTE, the target for initiating OPIDN, and $\mathrm{AChE}$, the target for producing cholinergic toxicity. RIP is defined here as $I C_{50}(\mathrm{AChE}) / \mathrm{IC}_{50}(\mathrm{NTE})$. By this definition, if the RIP is less than one, then the compound is predicted to produce cholinergic toxicity of sufficient severity that it cannot produce OPIDN at doses less than the $\mathrm{LD}_{50}$. However, if the RIP is greater than one, then the compound is predicted to produce OPIDN at doses less than the $\mathrm{LD}_{50}$ (Lotti and Johnson, 1978; Richardson, 1992; Richardson et al., 1993; Malygin et al., 2003; Wijeyesakere and Richardson, 2010).

*Correspondence to: Rudy J. Richardson, Computational Toxicology Laboratory, Toxicology Program, Department of Environmental Health Sciences, University of Michigan, Ann Arbor, Michigan 48109-2029, USA.

E-mail: rjrich@umich.edu

${ }^{a}$ Laboratory of Molecular Toxicology, Institute of Physiologically Active Compounds, Russian Academy of Sciences, Chernogolovka, Moscow Region, 142432, Russia

${ }^{b}$ Laboratory of Postgenomic Chemistry, Division of Chemical Enzymology, Chemistry Department, M.V. Lomonosov Moscow State University, 119991, Leninskie Gory, Moscow, Russia

'Toxicology Program, Department of Environmental Health Sciences, University of Michigan, Ann Arbor, Michigan, 48109, USA

${ }^{d}$ Department of Neurology, University of Michigan, Ann Arbor, Michigan 48109, USA 
The fact that an excellent correlation exists between inhibition/aging of NTE just after exposure and the appearance of OPIDN 1-4 weeks later is sufficient to use this information for the development of biomarkers and biosensors for delayed neuropathic agents (Richardson et al., 2015). The discovery of blood NTE in circulating lymphocytes and platelets (Dudek and Richardson, 1982; Richardson and Dudek, 1983; Bertoncin et al., 1985; Maroni and Bleecker, 1986) enabled it to be used as a biomarker of animal and human exposure to neuropathic OP compounds (Lotti, 1986, 1987; Lotti et al., 1983, 1986; Richardson and Dudek, 1983; Schwab and Richardson, 1986). Furthermore, the development of sensitive tyrosinase-based biosensors allowed us to measure NTE in whole blood (Sigolaeva et al., 2001; Sokolovskaya et al., 2005). The biosensor was used to establish correlations of NTE inhibitions in whole blood with that in lymphocytes and the brain $24 \mathrm{~h}$ after dosing hens with a neuropathic OP compound, O,O-dipropyl-Odichlorvinylphosphate (PrDChVP) (Makhaeva et al., 2003, 2007). These studies indicated that hen whole blood NTE can be assayed and used as a biomarker of exposure to neuropathic OP compounds (Sigolaeva et al., 2001; Makhaeva et al., 2003, 2007; Sokolovskaya et al., 2005).

For decades, the adult female chicken (hen) has been the most widely accepted in vivo model for the study of OPIDN and assessment of the neuropathic potential of OP compounds (Ehrich and Jortner, 2002). Standard laboratory rodents, mice and rats, have been thought to be resistant to OPIDN because they do not readily display clinical signs of hind limb paralysis despite the administration of high doses of neuropathic compounds (Abou-Donia, 1981; Veronesi et al., 1991). However, more detailed investigations showed that although mice and rats are resistant to clinical signs of ataxia and paralysis, they are susceptible to axonal lesions following neuropathic OP compound exposure. Moreover, the severity of structural damage to long axons in the spinal cord of rats and mice has been shown to correlate with the extent of NTE inhibition (Veronesi, 1984; Padilla and Veronesi, 1985; Mutch et al., 1995; Read et al., 2009, 2010).

Recently, we demonstrated that NTE from mouse and hen brain exhibits similar sensitivity to neuropathic OP compounds in vitro. Excellent correlations were obtained for inhibition kinetics in vitro of mouse brain enzymes vs. hen brain enzymes. Furthermore, inhibition of mouse brain AChE and NTE after dosing with $\mathrm{OP}$ compounds afforded $\mathrm{ED}_{50}$ ratios that agreed with RIP values assessed in vitro. Thus, mouse brain NTE and AChE could be used for biochemical assessment of the neuropathic potential of OP compounds both in vitro and in vivo (Makhaeva et al., 2014).

We undertook the present work as a further development of the mouse model for biochemical assessment of the ability of OP compounds to produce OPIDN. Our aims were twofold: (i) to investigate using mouse whole blood NTE as a biochemical marker for exposure to neuropathic OP compounds; and (2) to study the possibility of employing comparisons of NTE and AChE inhibition in mouse whole blood for assessing the risk of OPIDN in susceptible species exposed to neuropathic OP compounds.

We carried out these aims using two neuropathic OP compounds: O,O-di-1-propyl-O-2,2-dichlorvinyl phosphate (PrDChVP) and 0,0 -di-1-butyl-O-(1-trifluoromethyl-2,2,2-trifluoroethyl) phosphate (diBu-PFP) (Fig. 1) that differed in potency for producing acute cholinergic toxicity. PrDChVP has high acute cholinergic toxicity as well as a rather high neuropathic potential. It is a known neuropathic agent (Lotti and Johnson, 1978, Makhaeva et al., 1995). In contrast, although diBu-PFP has a high neuropathic

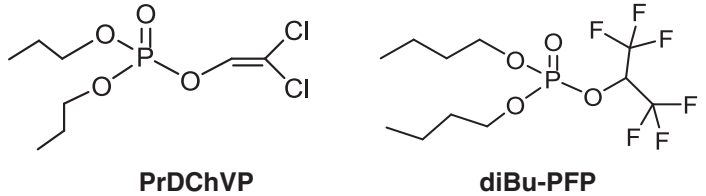

Figure 1. Structures of the test compounds.

potential in vitro and in vivo, it exhibits very low acute cholinergic toxicity as we have shown previously (Makhaeva et al., 2008, 2009 , 2014). We compared their inhibitory activities against mouse brain and blood AChE and NTE in vitro and in vivo $1 \mathrm{~h}$ after a single intraperitoneal (i.p.) administration of increasing doses of the compounds. In order to evaluate the possibility of using mouse blood enzymes for OPIDN risk assessment in vivo, we examined correlations between brain and blood inhibition of AChE and NTE produced by each compound. The $\mathrm{ED}_{50}$ values were determined from dose-response curves for mouse blood and brain AChE and NTE inhibition and the ratios $\mathrm{ED}_{50}(\mathrm{AChE}) / \mathrm{ED}_{50}(\mathrm{NTE})$ for blood and brain were compared.

\section{Materials and methods}

\section{Chemicals}

S-Acetylthiocholine iodide, ethopropazine hydrochloride and 5,5'-dithiobis(2-nitrobenzoic acid) were purchased from Sigma-Aldrich Co. (Steinheim, Germany). Phenyl valerate (PV), $N, N^{\prime}$-di-2-propylphosphorodiamidofluoridate (mipafox, MIP), O,O-di-1-propyl O-2,2-dichlorovinyl phosphate (PrDChVP) and O,O-di-1-butyl-O-(1-trifluoromethyl-2,2,2-trifluoroethyl) phosphate (diBu-PFP) were synthesized and characterized in the Institute of Physiologically Active Compounds, Russian Academy of Sciences (IPAC, RAS, Chernogolovka, Russia). Synthesis of diBu-PFP is described by Makhaeva et al. (2008, 2009). The purity of all substances produced by IPAC, RAS was $>99 \%$ by spectral and chromatographic analysis data. O,O-Diethyl-4-nitrophenyl phosphate (paraoxon, $\mathrm{PO}$ ) and protein standard (BSA) were from Sigma Chemical Co. (St. Louis, MO, USA). Poly $(\mathrm{N}, \mathrm{N}$-dimethylaminoethyl methacrylate), PDMAEMA 1600 (where the subscript denotes the number-average degrees of polymerization) with a molecular weight of $250000 \mathrm{~g} \mathrm{~mol}^{-1}$ and a polydispersity index of 2 was synthesized and characterized according to (Plamper et al., 2007; Steinschulte et al., 2012) and provided by Dr. Felix A. Plamper (RWTH Aachen University, Germany). All other chemicals were analytical grade and used without further purification. Aqueous solutions were prepared using deionized water.

\section{Tyrosinase biosensor fabrication}

Tyrosinase biosensors were fabricated according to the approaches described in (Sigolaeva et al., 2013a, 2014a) and used for the assay of NTE activity in blood. To fabricate tyrosinase biosensors, screen-printed electrodes (SPEs) were printed on poly(vinyl chloride) substrates of $0.2 \mathrm{~mm}$ thickness by means of conductive graphite paste (Gwent, UK) using a 200 mesh screen stencil. Each SPE consisted of a round-shaped working area ( $2.5 \mathrm{~mm}$ diameter), a conductive track $(30 \times 1.5 \mathrm{~mm})$, and a square extremity $(3 \times 7 \mathrm{~mm})$ for electrical contact. The $5 \mathrm{~g} \mathrm{I}^{-1}$ solution of PDMAEMA $_{1600}$ was prepared in $50 \mathrm{mM}$ sodium phosphate, $\mathrm{pH} 9$. Tyrosinase was prepared in $12.5 \mathrm{~g} \mathrm{I}^{-1}$ concentration in $10 \mathrm{mM}$ Tris, 
pH 7, immediately before the experiments. The PDMAEMA ${ }_{1600}$ was adsorbed onto SPEs by covering the working area of each SPE using a 10- $\mu$ ldrop of the PDMAEMA $A_{1600}$ solution, followed by $1 \mathrm{~h}$ adsorption. After that time, the SPEs were rinsed with Milli-Q water and dried using a stream of air. The tyrosinase was adsorbed in a similar way for $10 \mathrm{~min}$, followed by rinsing with Milli-Q water and drying with a stream of air. Tyrosinase biosensors were stored at $4^{\circ} \mathrm{C}$ until further use. Electrochemical experiments were performed at an ambient temperature in a one-compartment electrochemical cell with stirring (volume of $1 \mathrm{ml}$ ) in $0.05 \mathrm{M}$ sodium phosphate buffer with $0.1 \mathrm{M} \mathrm{NaCl}, \mathrm{pH}$ 7.0. A two-electrode configuration was used, where an SPE covered by PDMAEMA ${ }_{1600} /$ tyrosinase films with an active surface area of $0.049 \mathrm{~cm}^{2}$ served as the working electrode and $\mathrm{Ag} / \mathrm{AgCl}$ (length $1 \mathrm{~cm}$, diameter $3 \mathrm{~mm}$, and surface area $1.03 \mathrm{~cm}^{2}$ ) was used as a reference electrode. A potentiostat IPC-Micro (Kronas Ltd., Moscow, Russia) used for electrochemical measurements was interfaced with a desktop computer and electrochemical parameters were controlled by the potentiostat software furnished with the instrument.

\section{Animals}

All experiments with animal subjects were carried out according to protocols for the use and care of laboratory animals approved by the Institute of Physiologically Active Compounds, RAS (Chernogolovka, Russia). Adult outbred male CD-1 albino mice (20-24 g, 2 months of age) (Kennel Pushchino, Pushchino, Russia) were used. Mice were housed 6-8 per plastic shoebox cage at $22-24^{\circ} \mathrm{C}$ and fed mouse chow (Purina, St Louis, MO, USA; or Agro-range Ltd, Sergiev Posad, Russia) and tap water ad libitum.

\section{Preparation of brain and blood tissue for neuropathy target esterase and acetylcholinesterase assays}

Animals were euthanized via $\mathrm{CO}_{2}$ asphyxiation. The brains were immediately removed, weighed and frozen in liquid nitrogen; they were stored at $-70^{\circ} \mathrm{C}$ until use. The thawed brain samples were homogenized at $4{ }^{\circ} \mathrm{C}$ in five volumes of buffer $(50 \mathrm{mM}$ Tris- $\mathrm{HCl}$, 0.2 mM EDTA, pH 8.0) with a Potter homogenizer. The homogenates were centrifuged for $15 \mathrm{~min}$ at $9000 \times \mathrm{g}$ at $4{ }^{\circ} \mathrm{C}$ to prepare the 95 supernatant used for enzyme assay (Padilla and Veronesi, 1985). Aliquots of the supernatants (brain $9 S$ fraction) were stored at $-70^{\circ} \mathrm{C}$ until use. Mouse blood was obtained following decapitation after killing via $\mathrm{CO}_{2}$-induced asphyxiation. Trunk blood from each animal was collected immediately in glass vials containing citrate anticoagulant $(3.8 \% \mathrm{w} / \mathrm{v}$ sodium citrate; $0.2 \mathrm{ml}$ of citrate per $\mathrm{ml}$ of blood). All blood samples were aliquoted, frozen in liquid nitrogen and stored at $-70^{\circ} \mathrm{C}$ before use. For the preparation of whole blood hemolysates, thawed blood samples were diluted $1 / 100(v / v)$ in the appropriate diluting buffer (see below for buffer for each esterase) at $4{ }^{\circ} \mathrm{C}$. After careful stirring for $2 \mathrm{~min}$, the hemolyzed blood samples were aliquoted into $15-\mathrm{ml}$ polypropylene screw-cap tubes, immediately frozen in liquid nitrogen to ensure complete hemolysis and stored at $-20^{\circ} \mathrm{C}$ until use. Before analysis, the samples were thawed slowly in an ice-water bath.

\section{Acetylcholinesterase assay}

AChE activity in the brain and whole blood was determined in 95 brain supernatants and $1 / 100(v / v)$ blood hemolysates prepared in $0.1 \mathrm{M}$ sodium phosphate $\mathrm{pH}$ 7.5. Assays were carried out using the Ellman spectrophotometric method (Ellman et al., 1961) with modifications. Incubations were carried out in $0.1 \mathrm{M} \mathrm{Na} / \mathrm{K}$ phosphate $\mathrm{pH} 7.5$ at $37^{\circ} \mathrm{C}$ with $1 \mathrm{mM}$ acetylthiocholine iodide as a substrate in the presence of a selective inhibitor of $\mathrm{BChE}$, ethopropazine $(0.02 \mathrm{mM}, 10 \mathrm{~min}$ preincubation), for elimination of BChE activity (Padilla et al., 1999; Worek et al., 1999; Reiner et al., 2004).

For the AChE assay in hemolyzed blood, the standard Ellman assay wavelength of $412 \mathrm{~nm}$ was changed to $436 \mathrm{~nm}$ $\left(\varepsilon_{436}=10600 \mathrm{M}^{-1} \mathrm{~cm}^{-1}\right)$ to reduce interference from the high absorbance of hemoglobin (Worek et al., 1999). All data were automatically corrected for spontaneous hydrolysis of the substrate by carrying out absorbance measurements simultaneously in sample and reference cuvettes (3- $\mathrm{ml}$ volume, $1-\mathrm{cm}$ path length) at $37^{\circ} \mathrm{C}$ using a Gilford-250 spectrophotometer.

\section{Neuropathy target esterase assay}

Brain NTE activity was determined in $9 \mathrm{~S}$ supernatants by the colorimetric method of Johnson (Johnson, 1977) with slight modifications (Kayyali et al., 1991; Makhaeva et al., 2003). All reactions were carried out at $37^{\circ} \mathrm{C}$ for the entire assay. 9S supernatant $(50 \mu \mathrm{l})$ was diluted in $50 \mathrm{mM}$ Tris- $\mathrm{HCl}, 0.1 \mathrm{mM}$ EDTA, pH 8.0 at $37^{\circ} \mathrm{C}$. The suspension containing NTE along with other serine esterases was preincubated for 20 min with $50 \mu \mathrm{M}$ PO (final concentration in $500 \mu$ l total volume) to inhibit background esterase activity, and paired samples were preincubated for 20 min with $50 \mu \mathrm{M}$ PO and $250 \mu \mathrm{M}$ MIP (final concentrations in $500 \mu \mathrm{l}$ total volume) to completely inhibit NTE activity (Padilla and Veronesi, 1985). Thus, after adding substrate (PV), the difference in esterase activity between these two preincubation conditions corresponded to NTE activity. The preincubation was stopped by adding the substrate solution $(500 \mu \mathrm{l})$ of $2.8 \mathrm{mM} \mathrm{PV} / \mathrm{N}, \mathrm{N}^{\prime}$-dimethylformamide (PV/DMF) in $0.03 \%(w / v)$ Triton X-100, and the reaction was allowed to proceed for $20 \mathrm{~min}$, during which PV was hydrolyzed to produce phenol. A stop solution $(500 \mu \mathrm{l})$ of $1 \%(w / v)$ sodium dodecyl sulfate (SDS)/0.025\% ( $w / v)$ 4-aminoantipyrine (4-AAP) was added, and the reaction of 4-AAP with the phenol produced was allowed to proceed for $5 \mathrm{~min}$. The chromophore was produced by adding $250 \mu \mathrm{l}$ of $0.4 \%(w / v) \mathrm{K}_{3} \mathrm{Fe}(\mathrm{CN})_{6}$, and the color was allowed to develop and stabilize for $10 \mathrm{~min}$. The endpoint absorbance was measured at $486 \mathrm{~nm}\left(\varepsilon_{486}=16470 \mathrm{M}^{-1} \mathrm{~min}^{-1}\right)$ using a Bio-Rad Benchmark Plus microplate reader (Marnes-la-Coquette, France).

Blood NTE activity was determined in $1 / 100(\mathrm{v} / \mathrm{v})$ blood hemolysates according to the differential inhibition method of Johnson (Johnson, 1977) with an electrochemical endpoint as described previously (Sigolaeva et al., 2001, 2013b; Makhaeva et al., 2003). Briefly, 1/100 (v/v) blood hemolysate samples $(300 \mu \mathrm{l})$ were preincubated for $20 \mathrm{~min}$ at $37^{\circ} \mathrm{C}$ in $50 \mathrm{mM}$ Tris- $\mathrm{HCl} / 0.2 \mathrm{mM}$ EDTA (pH 8.0 at $37^{\circ} \mathrm{C}$ ) with $50 \mu \mathrm{M}$ PO (sample B) or $50 \mu \mathrm{M}$ PO plus $250 \mu \mathrm{M}$ MIP (sample C) (final inhibitor concentrations in a final volume of $400 \mu \mathrm{l}$ ). The PV substrate was added (in a final apparent concentration of $0.54 \mathrm{mM}$ and final volume of $500 \mu \mathrm{l}$ ), and the incubation was continued for the next $40 \mathrm{~min}$ at $37^{\circ} \mathrm{C}$. The reaction was stopped by addition of $100 \mu \mathrm{l}$ of $1 \%(w / v)$ aqueous SDS. The released phenol was assayed amperometrically after 20- to 50 -fold dilution of samples in $50 \mathrm{mM}$ sodium phosphate with $100 \mathrm{mM} \mathrm{NaCl}, \mathrm{pH}$ 7.0. The analytical signal was determined as the value of steady-state baseline current change (the difference between an average value of steady-state baseline 
current before and after analyte addition). Activity values were calculated using phenol calibration curves, obtained under the same conditions, and each was corrected for spontaneous hydrolysis of the substrate, determined separately. NTE activity was calculated as the difference in the amount of phenol released between samples $B$ and $C$.

\section{In vitro inhibition of acetylcholinesterase and neuropathy target esterase in mouse brain and blood preparations}

For measurement of NTE and AChE inhibition in vitro, pooled samples of mouse brain and blood were used. Stock solutions of the test compounds (PrDChVP and diBu-PFP) in a water-miscible organic solvent (DMSO) were serially diluted to appropriate working concentrations so that the final organic solvent concentration in the incubation mixture was $\leq 1 \%(\mathrm{v} / \mathrm{v})$, a concentration range previously shown to have no significant effect on enzyme activity. The $\mathrm{IC}_{50}$ values for the test compounds against brain and blood NTE and AChE were determined by 20-min incubation of mouse brain and blood samples with 10 to 12 different concentrations of either PrDChVP (from $10^{-11} \mathrm{M}$ to $10^{-5} \mathrm{M}$ ) or diBu-PFP (from $10^{-11} \mathrm{M}$ to $10^{-4} \mathrm{M}$ ) in working buffer. For NTE, test inhibitors were added at the end of the first preincubation interval with $\mathrm{PO}$ or PO + MIP, and inhibition was continued for 20 min before addition of PV substrate (Kropp and Richardson, 2003). Residual NTE and AChE activities in brain and blood preparations were measured as described above.

\section{In vivo inhibition of acetylcholinesterase and neuropathy target esterase in mouse brain and blood}

PrDChVP and diBu-PFP were dissolved in DMSO and injected once, i.p., in a volume of $0.1 \mathrm{ml}$ in increasing doses: $0.75,1.5,3,6,12,24$ and $36 \mathrm{mg} \mathrm{kg}^{-1}$ for PrDChVP and 0.5, 1, 2.5, 15, 30, 100, 250, 1000 and $2000 \mathrm{mg} \mathrm{kg}^{-1}$ for diBu-PFP. At least six animals were used for each dose. Because of the high cholinergic toxicity of PrDChVP, mice in this group were pretreated with atropine sulfate $20 \mathrm{~min}$ before PrDChVP injection ( $20 \mathrm{mg} \mathrm{kg}^{-1}$ in water, i.p.); in this case, the control animals received atropine sulfate and DMSO. In the experiment with diBu-PFP, the control animals were dosed only with DMSO. After $1 \mathrm{~h}$, the mice were decapitated under $\mathrm{CO}_{2}$ anesthesia. Preparation of brain and blood samples and assay methods for AChE and NTE are described above.

\section{Protein assay}

Protein was assayed by the Coomassie blue dye-binding method, with BSA as a standard (Bradford, 1976).

\section{Statistical analyses}

Data are expressed as the mean \pm SEM. Plots, linear correlations, and dose-response curve fitting were carried out using Origin 6.1 for Windows, OriginLab (Northampton, MA, USA). Independent $t$-tests were carried out using GraphPad Prism 6.05 for Windows, GraphPad Software (San Diego, CA, USA). The level of significance was set at $P<0.05$.

\section{Results}

\section{Inhibition of acetylcholinesterase and neuropathy target esterase by PrDChVP and diBu-PFP in mouse brain and blood in vitro}

Table 1 shows the experimental 20-min IC $C_{50}$ values for OP inhibitors PrDChVP and diBu-PFP against AChE and NTE from mouse brain and whole blood. PrDChVP had similar $\mathrm{IC}_{50}$ values across the two tissues for each enzyme (blood/brain ratios of 1.26 for AChE and 1.01 for NTE), whereas diBu-PFP IC 50 values were substantially higher in the blood (blood/brain ratios of 3.16 for $\mathrm{AChE}$ and 3.44 for NTE). The RIP values were greater than one in each case, indicating that both compounds would be expected to be neuropathic (Wijeyesakere and Richardson, 2010). Of particular interest is the fact that for each compound, the brain and blood RIP values were not significantly different from each other ( $t$-test, $P>0.05$ ).

\section{Inhibition of acetylcholinesterase and neuropathy target esterase by PrDChVP and diBu-PFP in mouse brain and blood in vivo}

Inhibition of NTE and AChE in mouse brain and blood was determined $1 \mathrm{~h}$ after i.p. administration of increasing doses of each of the two test OP compounds, PrDChVP and diBu-PFP. The data obtained from these in vivo experiments are shown in Fig. 2. As can be seen, both PrDChVP and diBu-PFP inhibited NTE and AChE in mouse brain and blood in a dose-dependent manner. Moreover, over the linear ranges of the dose-response curves, there were strong correlations between brain and blood inhibitions for each enzyme and each compound (Fig. 3).

By analyzing the dose-response curves in Fig. 2, the $\mathrm{ED}_{50}$ values for inhibition of AChE and NTE in mouse brain and blood by PrDChVP and diBu-PFP were obtained, and the ratios $\mathrm{ED}_{50}(\mathrm{AChE}) / \mathrm{ED}_{50}(\mathrm{NTE})$ were calculated as shown in Table 2. This ratio for brain enzymes in vivo can be considered a counterpart of the in vitro RIP (Richardson, 1992; Malygin et al., 2003). Accordingly, in agreement with our results for the in vitro RIP values, the $\mathrm{ED}_{50}$ ratios for each compound were greater than one, again indicating that the compounds would be expected to be neuropathic. Moreover, for each compound, there was no significant difference between brain and blood $\mathrm{ED}_{50}$ ratios ( $t$-test; $P>0.05$ ).

\section{Discussion}

The results of the present study support our hypothesis that mouse blood NTE could serve as a biochemical marker of exposure to neuropathic OP compounds and that relative inhibition of AChE and NTE in mouse blood could be used to assess the risk of OPIDN in susceptible species that might be exposed to neuropathic OP compounds.

The OP compounds selected for this investigation were PrDChVP and diBu-PFP (Fig. 1). PrDChVP produces OPIDN in hens with a minimal neuropathic dose of $0.6 \mathrm{mg} \mathrm{kg}^{-1}$ (Lotti and Johnson, 1978; Makhaeva et al., 1995). It has a rather high neuropathic potential with an RIP first reported to be 2.6 (Lotti and Johnson, 1978), in more recent work as 3.47 (Makhaeva et al., 2014), and in the present study as 3.89 (brain) and 4.80 (blood). In addition, PrDChVP has high acute toxicity, with an $\mathrm{LD}_{50}$ of $10 \mathrm{mg} \mathrm{kg}^{-1}$ in hens (Albert and Stearns, 1974) and $15 \mathrm{mg} \mathrm{kg}^{-1}$ in mice 
Table 1. Twenty-minute $I C_{50}$ values and relative inhibitor potencies (RIP) for organophosphorus (OP) inhibitors against acetylcholinesterase (AChE) and neuropathy target esterase (NTE) from preparations of mouse brain and blood ${ }^{a}$

\begin{tabular}{|c|c|c|c|c|c|c|}
\hline \multirow[t]{2}{*}{ Inhibitor } & \multicolumn{2}{|c|}{ Brain $\mathrm{IC}_{50}, \mathrm{nM}$} & \multicolumn{2}{|c|}{ Blood IC $50, \mathrm{nM}$} & \multicolumn{2}{|c|}{$\mathrm{RIP}=\mathrm{I} \mathrm{C}_{50}(\mathrm{AChE}) / \mathrm{I} \mathrm{C}_{50}(\mathrm{NTE})$} \\
\hline & AChE & NTE & AChE & NTE & Brain & Blood \\
\hline PrDChVP & $97.6 \pm 6.4$ & $25.1 \pm 2.1$ & $123 \pm 4$ & $25.4 \pm 2.5$ & $3.89 \pm 0.34$ & $4.80 \pm 0.49$ \\
\hline diBu-PFP & $494 \pm 29$ & $66.3 \pm 4.1$ & $1560 \pm 120$ & $228 \pm 17$ & $7.45 \pm 0.64$ & $6.80 \pm 0.73$ \\
\hline
\end{tabular}

a Values are the mean $\pm \operatorname{SEM}(n=3)$ from determinations on mouse brain 9S supernatants and mouse whole blood hemolysates.
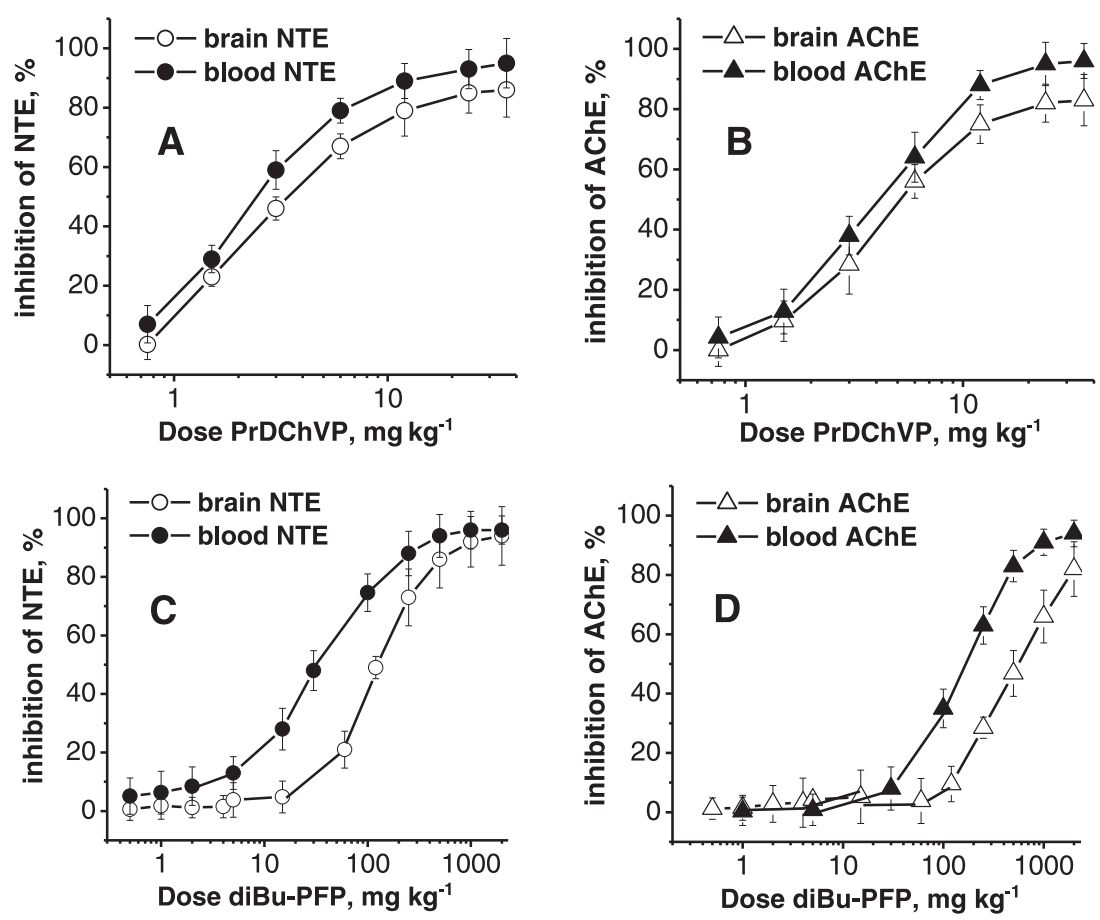

Figure 2. Dose-related neuropathy target esterase (NTE) and acetylcholinesterase (AChE) inhibition in brain and blood of mice given $O, O$-dipropylO-dichlorvinylphosphate (PrDChVP) (A, B) and O,O-di-1-butyl-O-(1-trifluoromethyl-2,2,2-trifluoroethyl) phosphate (diBu-PFP) (C, D) $1 \mathrm{~h}$ after dosing intraperitoneally (i.p.). Results are \% control (mean $\pm \mathrm{SEM} ; n=5$ to 6). Control brain, $\mathrm{nmol} /(\mathrm{min} \times \mathrm{mg}$ protein): $\mathrm{AChE}=74.4 \pm 4.0(n=10) ; \mathrm{NTE}=14.5$ $\pm 0.36(n=8)$. Control blood, $\mathrm{nmol} /(\mathrm{min} \times \mathrm{ml}$ blood $): \mathrm{AChE}=829 \pm 35(n=18), \mathrm{NTE}=18 \pm 2(n=8)$.

(Makhaeva et al., 2014). PrDChVP was intensively studied in our previous experiments in vitro and in vivo in hens and rats (Makhaeva et al., 1995, 2003, 2007). Moreover, we previously used PrDChVP as a known neuropathic agent to develop a mouse model for biochemical assessment of neuropathic potential (Rudakova et al., 2012; Makhaeva et al., 2014). Thus, in the current investigation, PrDChVP was used with high confidence as a compound with both high neuropathic potential and high cholinergic toxicity to investigate NTE and AChE inhibition in mouse blood compared with inhibition of these enzymes in mouse brain.

The second compound used in the present study was diBu-PFP. In our preliminary experiments in vitro, diBu-PFP exhibited a high neuropathic potential with an RIP of 4.99 (Makhaeva et al., 2008, 2009). More recently, we further evaluated diBu-PFP for inhibition of mouse brain NTE and AChE in vitro and in vivo, confirming its high neuropathic potency (Rudakova et al., 2012; Makhaeva et al., 2014). This trend was borne out in the present study with an RIP of 7.45 (brain) and 6.80 (blood). However, in contrast to PrDChVP, diBuPFP has low acute toxicity, with an $\mathrm{LD}_{50}$ (i.p.) in mice $>2000 \mathrm{mg} \mathrm{kg}^{-1}$ (Makhaeva et al., 2014; Rudakova et al., 2013).
AChE (Massoulié et al., 2008) and NTE (Moser et al., 2000) are each encoded by their single respective genes in mammals (including humans and mice), and the molecular forms of each enzyme expressed in different tissue compartments such as brain and blood have identical or highly similar intrinsic responses to inhibitors (Vose et al., 2008; Herkert et al., 2012). However, when certain extrinsic factors are present, such as other enzymes that bind or hydrolyze OP inhibitors, inhibitory potency will appear to decrease (i.e. $\mathrm{IC}_{50}$ values will increase) as demonstrated for chlorpyrifos oxon against rat brain $\mathrm{AChE}$ in the presence or absence of plasma or liver homogenate (Chanda et al., 1997; Mortensen et al., 1998).

Whereas the apparent inhibitory potency of PrDChVP against brain enzymes was similar to that against blood enzymes, this was not the case for diBu-PFP, which exhibited lower apparent inhibitory potency against blood enzymes than it did against brain enzymes (Table 1). The reasons for the lower apparent potency of diBu-PFP toward blood AChE and NTE were not directly evaluated in the present study. However, given the higher hydrophobicity of diBu-PFP and higher potency toward serum carboxylesterase and butyrylcholinesterase compared with $\mathrm{AChE}$ and NTE (Makhaeva et al., 2008), the concentration of diBu-PFP 

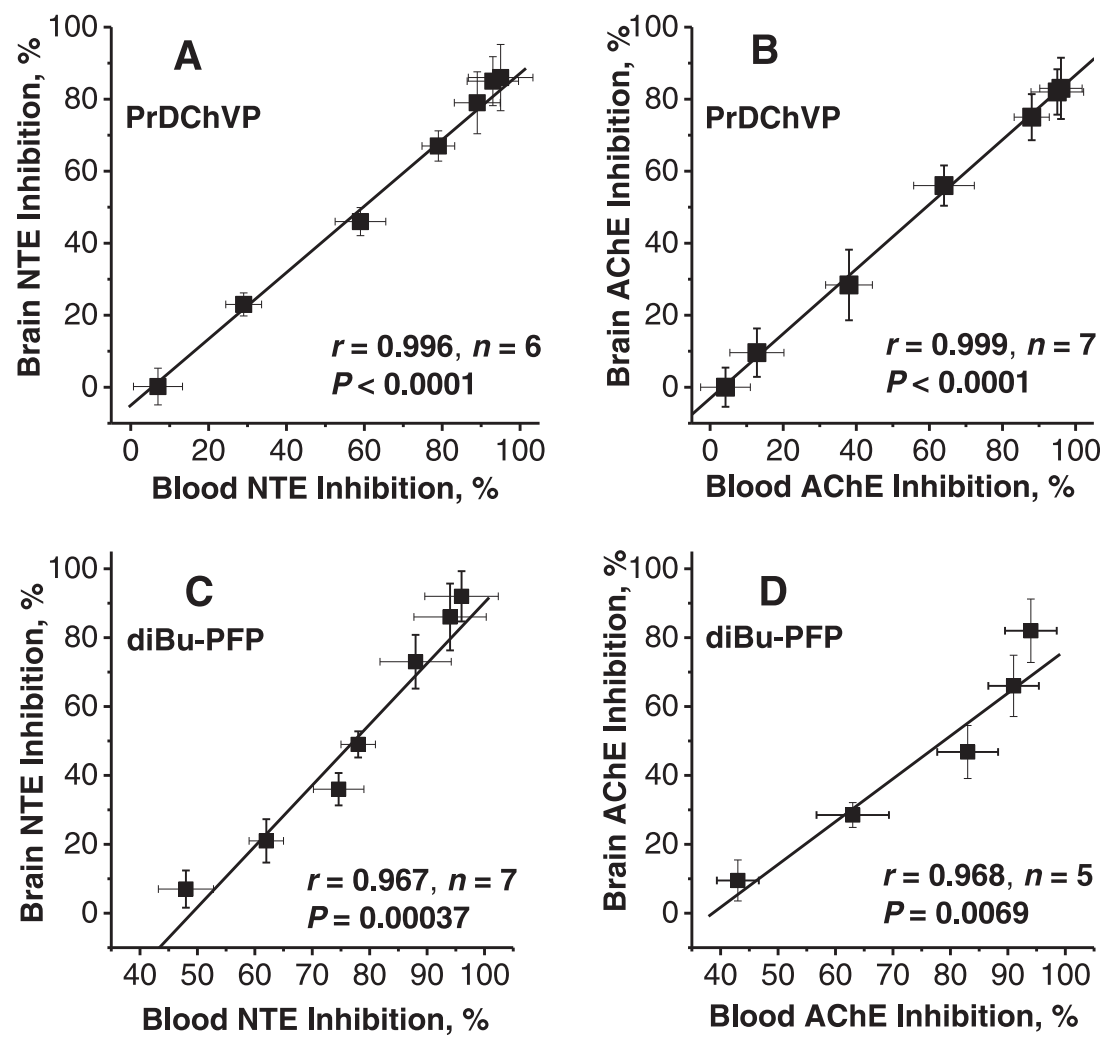

Figure 3. Correlations between brain and blood inhibition $1 \mathrm{~h}$ after dosing mice with $O, O$-dipropyl-O-dichlorvinylphosphate (PrDChVP): (A) neuropathy target esterase (NTE); (B) acetylcholinesterase (AChE). Correlations between brain and blood inhibition $1 \mathrm{~h}$ after dosing mice with 0,0 -di-1-butyl-O-(1trifluoromethyl-2,2,2-trifluoroethyl) phosphate (diBu-PFP): (C) NTE; (D) AChE.

Table 2. $E D_{50}$ values of organophosphorus (OP) compounds against acetylcholinesterase (AChE) and neuropathy target esterase (NTE) in mouse brain and blood $1 \mathrm{~h}$ after intraperitoneal (i.p.) dosing and calculated $\mathrm{ED}_{50}$ ratios ${ }^{\mathrm{a}}$

\begin{tabular}{|c|c|c|c|c|c|c|}
\hline \multirow[b]{2}{*}{ Compound } & \multicolumn{2}{|c|}{ Brain $\mathrm{ED}_{50}, \mathrm{mg} / \mathrm{kg}$} & \multicolumn{2}{|c|}{ Blood $\mathrm{ED}_{50}, \mathrm{mg} / \mathrm{kg}$} & \multicolumn{2}{|c|}{$\mathrm{ED}_{50}(\mathrm{AChE}) / \mathrm{ED}_{50}(\mathrm{NTE})$} \\
\hline & AChE & NTE & AChE & NTE & Brain & Blood \\
\hline $\begin{array}{l}\text { PrDChVP } \\
\text { diRu-PFP }\end{array}$ & $\begin{array}{r}4.06 \pm 0.09 \\
4994+538\end{array}$ & $\begin{array}{r}1.92 \pm 0.16 \\
12161+345\end{array}$ & $\begin{array}{r}4.0 \pm 0.12 \\
1544+49\end{array}$ & $2.01 \pm 0.11$ & $2.1 \pm 0.18$ & $2.0 \pm 0.13$ \\
\hline
\end{tabular}

a Values are the mean $\pm \operatorname{SEM}(n=5$ to 6$)$. $\mathrm{ED}_{50}$ values were determined from analyses of dose-response curves in Fig. 2. Brain assays were carried out with 95 supernatants from mouse brain homogenates. Blood assays were carried out with mouse whole blood hemolysates.

could have been preferentially lowered because of binding to these enzymes as well as to serum albumin (Duysen et al., 2012; Tarhoni et al., 2008). In addition, serum paraoxonase (PON1) hydrolyzes a number of OP compounds (Costa et al., 2003), and it is possible that diBu-PFP is a better substrate than PrDChVP for serum paraoxonase1 (PON1), a hypothesis to be tested in future work.

Despite the differential response of blood enzymes to the two inhibitors, the brain and blood RIP values were not statistically different from each other for each inhibitor (Table 1). This is to be expected, because if the concentration of diBu-PFP were decreased in blood, the consequent increase in $\mathrm{IC}_{50}$ between brain and blood should be similar for AChE and NTE; in fact, the observed fold increases were 3.16 (AChE) and 3.44 (NTE). Thus, these differences would nearly cancel when the RIP values were calculated. In any event, for both compounds, the brain and blood RIP values are in agreement and the fact that these ratios are greater than one is consistent with the known neuropathic potential of these compounds (Wijeyesakere and Richardson, 2010; Makhaeva et al., 2014).

Just as blood AChE inhibition has been recommended and employed as a surrogate for brain AChE inhibition and a biomarker of exposure to cholinergic OP compounds (Carlock et al., 1999; Chen et al., 1999), we hypothesized that inhibition of mouse blood NTE reflects brain NTE inhibition and serves as a biochemical marker of exposure to neuropathic OP compounds, as demonstrated for inhibition of NTE in hen and human blood (Lotti, 1986; Makhaeva et al., 2003). These expectations were confirmed by our results, which showed dose-related increases in AChE and NTE inhibition (Fig. 2) that were highly correlated between brain and blood (Fig.3). However, as summarized in Table 2, whereas the $\mathrm{ED}_{50}$ values for PrDChVP were the same for respective brain and blood 
enzymes, these values for diBu-PFP were higher in the brain by a factor of 3.23 for AChE and 3.37 for NTE. The differences between in vivo sensitivities of brain and blood enzymes to diBu-PFP were of similar magnitude to the observed differences in vitro but in the opposite direction. Such apparent paradoxes are not unusual. As pointed out by Chanda et al. (1997), the pattern of inhibition of esterases in vivo can be quite different from what is seen in vitro. Moreover, the pharmacokinetic factors governing such differences will, in general, be highly compound-specific (Maxwell, 1992). Nevertheless, in a similar manner to the cancellation of systematic differences between brain and blood $I C_{50}$ values when RIP ratios were calculated (Table 1), the same behavior was seen with systematic differences between brain and blood $\mathrm{ED}_{50}$ values when these ratios were calculated (Table 2 ). As was the case for RIP values based on $\mathrm{IC}_{50}$ ratios, the $E D_{50}$ ratios for each compound were the same for brain and blood enzymes. Moreover, the ratios were greater than one, consistent with the known neuropathic potential of the compounds (Wijeyesakere and Richardson, 2010; Makhaeva et al., 2014).

In conclusion, the data presented and discussed above allow us to consider mouse blood NTE as a biochemical marker of exposure to neuropathic OP compounds. Moreover, inhibition of NTE in the blood can be used in conjunction with inhibition of blood AChE to assess the likelihood that an exposure of a susceptible species to an OP compound would produce cholinergic and/or delayed neuropathic effects.

\section{Acknowledgments}

The authors gratefully acknowledge the support of this work by the NATO Science for Peace and Security Program (Grant No. SfP 984082) and the Russian Foundation for Basic Research (Grant No. 14-03-01063). The authors thank our colleagues from IPAC RAS Dr. Alexey Aksinenko for the synthesis of compounds for research as well as Ms. Tatyana Galenko and Ms. Olga Serebryakova for their assistance with the experiments on mice. The authors acknowledge Dr. Felix A. Plamper from RWTH, Aachen University, Germany, for the poly(N,Ndimethylaminoethyl methacrylate) for tyrosinase biosensor fabrication.

\section{Conflict of interest}

The Authors did not report any conflict of interest.

\section{References}

Abou-Donia MB. 1981. Organophosphorus ester-induced delayed neurotoxicity. Annu. Rev. Pharmacol. Toxicol. 21: 511-548. DOl:10.1146/ annurev.pa.21.040181.002455.

Albert JR, Stearns SM. 1974. Delayed neurotoxic potential of a series of alkyl esters of 2,2-dichlorovinyl phosphoric acid in the chicken. Toxicol. Appl. Pharmacol. 29: 136.

Bertoncin D, Russolo A, Caroldi S, Lotti M. 1985. Neuropathy target esterase in human lymphocytes. Arch. Environ. Health 40: 221-230.

Bradford MM. 1976. A rapid and sensitive method for the quantitation of microgram quantities of protein utilizing the principle of protein-dye binding. Anal. Biochem. 72: 248-254.

Carlock LL, Chen WL, Gordon EB, Killeen JC, Manley A, Meyer LS, Mullin LS, Pendino KJ, Percy A, Sargent DE, Seaman LR, Svanborg NK, Stanton RH, Tellone Cl, van Goethem DL. 1999. Regulating and assessing risks of cholinesterase-inhibiting pesticides: divergent approaches and interpretations. J. Toxicol. Environ. Health $B$ 2: $105-160$.

Chanda SM, Mortensen SR, Moser VC, Padilla S. 1997. Tissue-specific effects of chlorpyrifos on carboxylesterase and cholinesterase activity in adult rats: an in vitro and in vivo comparison. Fundam. Appl. Toxicol. 38: 148-157.

Chen WL, Sheets JJ, Nolan RJ, Mattsson JL. 1999. Human red blood cell acetylcholinesterase inhibition as the appropriate and conservative surrogate endpoint for establishing chlorpyrifos reference dose. Regul. Toxicol. Pharmacol. 29: 15-22.

Costa LG, Richter RJ, Li WF, Guizzetti M, Furlong CE. 2003. Paraoxonase (PON1) as a biomarker of susceptibility for organophosphate toxicity. Biomarkers 8: 1-12.

Dudek BR, Richardson RJ. 1982. Evidence for the existence of neurotoxic esterase in neuronal and lymphatic tissue of the adult hen. Biochem. Pharmacol. 31: 1117-1121.

Duysen EG, Cashman JR, Schopfer LM, Nachon F, Masson P, Lockridge O. 2012. Differential sensitivity of plasma carboxylesterase-null mice to parathion, chlorpyrifos and chlorpyrifos oxon, but not to diazinon, dichlorvos, diisopropylfluorophosphate, cresyl saigenin phosphate, cyclosarin thiocholine, tabun thiocholine, and carbofuran. Chem. Biol. Interact. 195: 189-198. DOI:10.1016/j. cbi.2011.12.006.

Ehrich E, Jortner BS. 2002. Organophosphate-induced delayed neuropathy. In Handbook of Neurotoxicology, Ej M (ed), Vol. 1. Humana Press: Totowa; 17-27.

Ellman G, Courtney KD, Andres V, Jr, RM F. 1961. A new and rapid colorimetric determination of acetylcholinesterase activity. Biochem. Pharmacol. 7: 88-95. DOI:10.1016/00006-2952(61)90145-9.

Herkert NM, Freude G, Kunz U, Thiermann H, Worek F. 2012. Comparative kinetics of organophosphates and oximes with erythrocyte, muscle and brain acetylcholinesterase. Toxicol. Lett. 209: 173-178. DOI:10.1016/j.toxlet.2011.12.015.

Johnson MK. 1977. Improved assay of neurotoxic esterase for screening organophosphates for delayed neurotoxicity potential. Arch. Toxicol. 37: 113-115.

Johnson MK. 1982. The target for initiation of delayed neurotoxicity by organophosphorus esters: biochemical studies and toxicological applications. In Reviews in Biochemical Toxicology, Hodgson E, Bend JR, Philpot RM (eds), Vol. 4. Elsevier: Amsterdam; $141-212$.

Kayyali US, Moore TB, Randall JC, Richardson RJ. 1991. Neurotoxic esterase (NTE) assay: optimized conditions based on detergent-induced shifts in the phenol/4-aminoantipyrine chromophore spectrum. J. Anal. Toxicol. 15: 86-89.

Kropp TJ, Richardson RJ. 2003. Relative inhibitory potencies of chlorpyrifos oxon, chlorpyrifos methyl oxon, and mipafox for acetylcholinesterase versus neuropathy target esterase. J. Toxicol. Environ. Health A 66: 1145-1157. DOI:10.1080/15287390306360.

Lotti M 1986. Biological monitoring for organophosphate-induced delayed polyneuropathy. Toxicol. Lett. 33: 167-172.

Lotti M 1987. Organophosphate-induced delayed polyneuropathy in humans: Perspectives for biomonitoring. Trends Pharmacol. Sci. 81: 176-177.

Lotti M 1992. The pathogenesis of organophosphate polyneuropathy. Crit. Rev. Toxicol. 21: 465-487.

Lotti M, Johnson MK. 1978. Neurotoxicity of organophosphorus pesticides: predictions can be based on in vitro studies with hen and human enzymes. Arch. Toxicol. 41: 215-221. DOI:10.1007/BF00354093.

Lotti M, Moretto A. 2005. Organophosphate-induced delayed polyneuropathy. Toxicol. Rev. 24: 37-49.

Lotti M, Becker CE, Aminoff MJ, Woodrow JE, Seiber JN, Talcott RE, Richardson RJ. 1983. Occupational exposure to the cotton defoliants DEF and merphos. A rational approach to monitoring organophosphorusinduced neurotoxicity. J. Occup. Med. 25: 517-522.

Lotti M, Moretto A, Zoppellari R, Dainese R, Rizzuto N, Barusco G. 1986. Inhibition of lymphocytic neuropathy target esterase predicts the development of organophosphate-induced delayed polyneuropathy. Arch. Toxicol. 59: 176-179.

Makhaeva GF, Filonenko IV, Malygin VV. 1995. A comparative study of the interaction of phosphoric acid dichlorovinyl esters with a neurotoxic esterase from the brain of hens and rats. Zh. Evol. Biokhim. Fiziol. 4: 396-403[Article in Russian].

Makhaeva GF, Sigolaeva LV, Zhuravleva LV, Eremenko AV, Kurochkin IN, Malygin VV, Richardson RJ. 2003. Biosensor detection of neuropathy target esterase in whole blood as a biomarker of exposure to neuropathic organophosphorus compounds. J. Toxicol. Environ. Health A 66: 599-610. DOI:10.1080/152839030906375.

Makhaeva GF, Malygin VV, Strakhova NN, Sigolaeva LV, Sokolovskaya LG, Eremenko AV, Kurochkin IN, Richardson RJ. 2007. Biosensor assay of 
neuropathy target esterase in whole blood as a new approach to OPIDN risk assessment: review of progress. Hum. Exp. Toxicol. 26: 273-282. DOI:10.1177/0960327106070463.

Makhaeva GF, Serebryakova OG, Boltneva NP, Galenko TG, Aksinenko AY Sokolov VB, Martynov IV. 2008. Esterase profile and analysis of structure-inhibitor selectivity relationships for homologous phosphorylated 1-hydroperfluoroisopropanols. Dokl. Biochem. Biophys. 423: 352357. DOI:10.1134/S1607672908060094.

Makhaeva GF, Aksinenko AY, Sokolov VB, Serebryakova OG, Richardson RJ. 2009. Synthesis of organophosphates with fluorine-containing leaving groups as serine esterase inhibitors with potential for Alzheimer disease therapeutics. Bioorg. Med. Chem. Lett. 19: 5528-5530. DOl:10.1016/j. bmcl.2009.08.065.

Makhaeva GF, Rudakova EV, Hein ND, Serebryakova OG, Kovaleva NV, Boltneva NP, Fink JK, Richardson RJ. 2014. Further studies toward a mouse model for biochemical assessment of neuropathic potential of organophosphorus compounds. J. Appl. Toxicol. 34(12): 1426-1435. DOI:10.1002/jat.2977.

Malygin VV, Sokolov VB, Richardson RJ, Makhaeva GF. 2003. Quantitative structure-activity relationships predict the delayed neurotoxicity potential of a series of $\mathrm{O}$-alkyl-O-methylchloroformimino phenylphosphonates. J. Toxicol. Environ. Health A 66: 611-625. DOI:10.1080/15287390309353770.

Maroni M, Bleecker ML. 1986. Neuropathy target esterase in human lymphocytes and platelets. J. Appl. Toxicol. 6: 1-7.

Massoulié J, Perrier N, Noureddine H, Liang D, Bon S. 2008. Old and new questions about cholinesterases. Chem. Biol. Interact. 175: 30-44. DOI:10.1016/j.cbi.2008.04.039.

Maxwell DM. 1992. The specificity of carboxylesterase protection against the toxicity of organophosphorus compounds. Toxicol. Appl. Pharmacol. 114: 306-312.

Mortensen SR, Brimijoin S, Hooper MJ, Padilla S. 1998. Comparison of the in vitro sensitivity of rat acetylcholinesterase to chlorpyrifos-oxon: what do tissue IC50 values represent? Toxicol. Appl. Pharmacol. 148: 46-49.

Moser M, Stempfl T, Li Y, Glynn P, Büttner R, Kretzschmar D. 2000. Cloning and expression of the murine sws/NTE gene. Mech. Devel. 90: 279-282.

Mutch E, Kelly SS, Blain PG, Williams FM. 1995. Comparative studies of two organophosphorus compounds in the mouse. Toxicol. Lett. 81(1): 45-53.

Padilla S, Veronesi B. 1985. The relationships between neurological damage and neurotoxic esterase inhibition in rats acutely exposed to tri-ortho-cresyl phosphate. Toxicol. Appl. Pharmacol. 78: 78-87.

Padilla S, Lassiter TL, Hunter D. 1999. Neurodegeneration Methods and Protocols. In Methods in Molecular Medicine Vol. 22, Harry J, Tilson HA (eds). Humana Press: Totowa; 237-245.

Plamper FA, Ruppel M, Schmalz A, Borisov OV, Ballauff M, Müller AHE. 2007. Tuning the Thermoresponsive Properties of Weak Polyelec trolytes: Aqueous Solutions of Star-Shaped and Linear Poly $(\mathrm{N}, \mathrm{N}$ dimethylaminoethyl Methacrylate). Macromolecules 40(23): 8361-8366. DOI:10.1021/ma071203b.

Read DJ, Li Y, Chao MV, Cavanagh JB, Glynn P. 2009. Neuropathy target esterase is required for adult vertebrate axon maintenance. J. Neurosci. 29: 11594-11600.

Read DJ, Li Y, Chao MV, Cavanagh JB, Glynn P. 2010. Organophosphates induce distal axonal damage, but not brain oedema, by inactivating neuropathy target esterase. Toxicol. Appl. Pharmacol. 245: 108-115.

Reiner E, Bosak A, Simeon-Rudolf V. 2004. Activity of cholinesterases in human whole blood measured with acetylthiocholine as substrate and ethopropazine as selective inhibitor of plasma butyrylcholinesterase. Arh. Hig. Rada Toksikol. 55: 1-4.

Richardson RJ. 1992. Interactions of organophosphorus compounds with neurotoxic esterase. In Organophosphates: Chemistry, Fate, and Effects, Chambers JE, Levi PE (eds). Academic Press: San Diego; 299-323.

Richardson RJ, Dudek BR. 1983. Neurotoxic esterase: Characterization and potential for a predictive screen for exposure to neuropathic organophosphates. In Pesticide Chemistry: Human Welfare and the Environment Vol 3, Miyamoto J, Pc K (eds). Pergamon: Oxford; 491-495.

Richardson RJ, Makhaeva GF. 2014. Organophosphorus compounds. In Encyclopedia of Toxicology, Wexler P (ed), 3nd edn, Vol. 3. Elsevier, Ltd.: Oxford; 714-719.
Richardson RJ, Moore TB, Kayyali US, Fowke JH, Randall JC. 1993. Inhibition of hen brain acetylcholinesterase and neurotoxic esterase by chlorpyrifos in vivo and kinetics of inhibition by chlorpyrifos oxon in vitro: application to assessment of neuropathic risk. Fundam. Appl. Toxicol. 20: 273-279. DOI:10.1006/faat.1993.1036.

Richardson RJ, Hein ND, Wijeyesakere SJ, Fink JK, Makhaeva GF. 2013. Neuropathy target esterase (NTE): overview and future. Chem. Biol. Interact. 203: 238-244.

Richardson RJ, Worden RM, Wijeyesakere SJ, Hein ND, Fink JK, Makhaeva GF. 2015. Neuropathy target esterase as a biomarker and biosensor of delayed neuropathic agents. In Handbook of Toxicology of Chemical Warfare Agents, Gupta RC (ed), 2nd edn. Elsevier: Amsterdam; 935-952.

Rudakova EV, Serebryakova OG, Boltneva NP, Galenko TG, Makhaeva GF. 2012. A biochemical model in mice for assessment of neuropathic potential of organophosphorus compounds. Toxicol. Rev. 6: 20-24[Article in Russian].

Rudakova EV, Makhaeva GF, Galenko TG, Aksinenko AY, Sokolov VB, Martynov IV. 2013. A new selective inhibitor of mouse blood plasma carboxylesterase. Dokl. Biochem. Biophys. 449: 87-89.

Schwab BW, Richardson RJ. 1986. Lymphocyte and brain neurotoxic esterase: Dose and time dependence of inhibition in the hen examined with three organophosphorus esters. Toxicol. Appl. Pharmacol. 83: 1-9.

Sigolaeva LV, Makower A, Eremenko AV, Makhaeva GF, Malygin VV Kurochkin IN, Scheller FW. 2001. Bioelectrochemical analysis of neuropathy target esterase activity in blood. Anal. Biochem. 290: 1-9.

Sigolaeva LV, Pergushov DV, Synatschke CV, Wolf A, Dewald I, Kurochkin IN, Fery A, Müller AHE. 2013a. Co-assemblies of micelle-forming diblock copolymers and enzymes on graphite substrate for an improved design of biosensor systems. Soft Matter 9: 2858-2868.

Sigolaeva LV, Dubacheva GV, Porus MV, Eremenko AV, Rudakova EV, Makhaeva GF, Richardson RJ, Kurochkin IN. 2013b. A layer-by-layer tyrosinase biosensor for assay of carboxylesterase and neuropathy target esterase activities in blood. Anal. Methods 5: 3872-3879.

Sigolaeva LV, Gladyr SY, Gelissen APH, Mergel O, Pergushov DV, Kurochkin IN, Plamper FA, Richtering W. 2014a. Dual-stimulisensitive microgels as a tool for stimulated spongelike adsorption of biomaterials for biosensor applications. Biomacromolecules 15: 3735-3745.

Sigolaeva LV, Günther U, Pergushov DV, Gladyr SY, Kurochkin IN, Schacher FH. 2014b. Sequential pH-dependent adsorption of ionic amphiphilic diblock copolymer micelles and choline oxidase onto conductive substrates: towards the design of biosensors. Macromol. Biosci. 14(7): 1039-1051.

Sokolovskaya LG, Sigolaeva LV, Eremenko AV, Gachok IV, Makhaeva GF, Strakhova NN, Malygin VV, Richardson RJ, Kurochkin IN. 2005. Improved electrochemical analysis of neuropathy target esterase activity by a tyrosinase carbon paste electrode modified by 1-methoxyphenazine methosulfate. Biotechnol. Lett. 27: 1211-1218.

Steinschulte AA, Schulte B, Erberich M, Borisov OV, Plamper FA. 2012. Unimolecular Janus Micelles by Microenvironment-Induced, Internal Complexation. ACS Macro Lett. 1: 504-507. DOI:10.1021/mz300043s.

Tarhoni MH, Lister T, Ray DE, Carter WG. 2008. Albumin binding as a potential biomarker of exposure to moderately low levels of organophosphorus pesticides. Biomarkers 13: 343-363.

Veronesi B 1984. A rodent model of organophosphorus-induced delayed neuropathy: distribution of central (spinal cord) and peripheral nerve damage. Neuropathol. Appl. Neurobiol. 10: 357-368.

Veronesi B, Padilla S, Blackmon K, Pope C. 1991. A murine model of OPIDN: neuropathic and biochemical description. Toxicol. Appl. Pharmacol. 107: 311-324.

Vose SC, Fujioka K, Gulevich AG, Lin AY, Holland NT, Casida JE. 2008. Cellular function of neuropathy target esterase in lysophosphatidylcholine action. Toxicol. Appl. Pharmacol. 232: 376-383. DOl:10.1016/j. taap.2008.07.015.

Wijeyesakere SJ, Richardson RJ. 2010. Neuropathy target esterase. In Hayes' Handbook of Pesticide Toxicology, 3rd edn. Elsevier, Krieger R (ed). Academic Press: San Diego; 1435-1455.

Worek F, Mast U, Kiderlen D, Diepold C, Eyer P. 1999. Improved determination of acetylcholinesterase activity in human whole blood. Clin. Chim. Acta 288: 73-90. 